\title{
The Janus face of polypharmacy - overuse versus underuse of medication
}

\author{
Kirsten K. Viktil ${ }^{1,2}$, Hege Salvesen Blix ${ }^{2,3}$ and Åsmund Reikvam ${ }^{2}$ \\ 1) Diakonhjemmet Hospital Pharmacy, Oslo \\ 2) Department of Pharmacotherapeutics, Faculty of Medicine, University of Oslo, Oslo, Norway \\ 3) Department of Pharmacoepidemiology, Norwegian Institute of Public Health, Oslo \\ Correspondence: Kirsten K. Viktil, Department of Pharmacotherapeutics, Faculty of Medicine, University of Oslo, P.O.Box 1057, Blindern, \\ $\mathrm{N}-0316$ Oslo, Norway \\ E-mail: k.k.viktil@medisin.uio.no Telephone: +4722840298 Mobile: +4741332217 Telefax:+4722840202
}

\begin{abstract}
As modern guidelines may recommend several drugs for a single medical condition, it follows that many patients, especially if co-morbidity is present, use a number of medications. Also, an aging population implies more morbidity and consequently will have the result that many patients use many drugs - a situation often referred to as polypharmacy. Polypharmacy has been linked to negative health outcomes such as adverse drug reactions, interaction problems, poor patient adherence, and hospitalisations. Such experiences have led to the attitude that efforts should be made to reduce polypharmacy. However, this approach might prevent patients from obtaining optimal treatment. There is no universal definition of polypharmacy and measuring of a reduction in polypharmacy becomes problematic. Because polypharmacy is an imprecise term it should be used with caution in research as well as in patient management. Moreover, studies have shown that undertreatment occurs frequently also among patients using many drugs. This is the Janus face of polypharmacy: too many drugs should be avoided, but the individual patient should receive the appropriate drugs that have the potential to reduce morbidity and improve quality of life. It is the individual drugs themselves, along with patient specific factors, and not a fixed number of drugs, that we should pay attention to.
\end{abstract}

\section{INTRODUCTION}

Evidence based guidelines recommend several drugs in the treatment or the prevention of a single medical condition. This pertains to for instance treatment of heart failure and diabetes mellitus, prevention of new cardiovascular events after myocardial infarction, and prevention of the progression of rheumatoid arthritis. Further, the population is growing older, which implies more co-morbidity. Consequently, many people are in need of several medications - a situation often referred to as polypharmacy.

Polypharmacy is a widely used term and it has been used for many decades. A search in PubMed yielded more than 2000 hits on "polypharmacy" (October 2007). Polypharmacy has been used as an indicator to select patients for research projects, for quality assurance tasks, for example medication reviews, and for describing extensive drug use among patients (1-10).

In general, the term polypharmacy has been used with negative connotations. Therefore, in patient management a main focus has often been on reducing polypharmacy. But is less polypharmacy, the use of fewer drugs in an individual patient, always beneficial? Is it a relevant aim to reduce the total number of drugs, or to ensure that the number of medications over a period of time is not exceeded? Should the focus rather be on avoiding inappropriate drugs and on using appropriate drugs? In the following we will discuss these issues.

\section{DEFINITIONS}

The word "poly" is Greek and means many or much (11). However, the term polypharmacy has been given definitions connected both to the use of more than a certain number of drugs concomitantly and to the clinical appropriateness of drug use $(10,12-19)$. However, the most common definition refers to the use of more than a fixed number of drugs. Some researchers have made a distinction between minor (2-4 drugs) and major (five or more drugs) polypharmacy (13). The number could reflect the total numbers of drugs used in the patient's medication regimen, or it could refer to the number of drugs for a particular condition (15) which is often the case in studies of psychiatric disorders $(16,20)$. Further, in research studies, the number of drugs which are defined as polypharmacy varies from study to study: 2 or more drugs $(13,16,21), 3$ or more drugs (22), 5 or more drugs $(13,14,23,24), 6$ drugs $(9,25,26), 10$ or more drugs $(4,27)$. However, the most common definition is the use of 5 or more drugs (10). Others have underlined that when discussing polypharmacy, distinctions should be made between cumulative, continuous and simultaneous polypharmacy (28). These terms refer to the following: cumulative - the number of different medications that a patient has been given during a particular time window; continuous - estimates of the number of medications that are being taken permanently; simultaneous a measure of the number of medications a patient is 
receiving at any given time (28). Since there are different opinions about the definition of polypharmacy, it follows that it is an imprecise term and as such should be used with caution in research as well in patient management.

The other approach to define polypharmacy has suggested that it could refer to use of more drugs than are clinically indicated or use of drugs that are inappropriate for the patient (12). Terms as unnecessary polypharmacy and inappropriate polypharmacy have been used. But with regard to semantics, these descriptions are not in accordance with the word poly which means many. In the following we use polypharmacy in the sense that it refers to a countable number of drugs, and not to the appropriateness of the drugs.

\section{CAUSES OF POLYPHARMACY}

There are many possible reasons for the occurrence of polypharmacy. As already mentioned, treatment guidelines for various conditions recommend many drugs, based on the fact that drug combinations have improved the therapeutic response and decreased morbidity and mortality (29). An aging population implies more morbidity and will result in the use of many drugs. Patients may be consulting different physicians - both general practitioners and specialists - and the transfer of information on drug use is often not optimal, with the possibility that drug prescriptions are not coordinated. Furthermore, drugs are becoming more available to patients, for instance through more offers of drugs not requiring prescriptions (over the counter medications), and through drug availability on the internet. Also, today more conditions, for instance Alzheimer disease and various cancer diseases, can be treated than a few years ago.

\section{FREQUENCY OF POLYPHARMACY}

Studies exploring polypharmacy have been conducted in different clinical settings, in out-patients/ambulatory patients $(14,25,30-33)$, hospitalised patients $(26,34-$ $36)$, patients in nursing homes $(37,38)$, and elderly patients $(25-27,32,33,39)$. Studies have also been performed based on data from prescription or population databases $(13,28,40-42)$. Further, studies have explored polypharmacy in specific disease entities such as psychiatric diseases $(16,20,35)$, rheumatic diseases (34), asthma (42), and heart failure (43). Due to different settings and definitions given in the various studies, the frequency of polypharmacy varies widely. Figures from $8 \%$ in a population-based study (13) to nearly $80 \%$ in a clinical study among elderly (44) have been reported. In any case, it can be stated that the prevalence of patients using 5 or more drugs - the most common definition - is high, particularly among the elderly $(10,25,27,32-34,36,42,45)$. In general, more than half of the patients enrolled in theses studies used five or more drugs. In a study of patients hospitalised in departments of internal medicine our group found that $47.3 \%$ of the patients used five or more drugs (Figure 1) (36).

\section{CONSEQUENCES OF POLYPHARMACY}

Studies have shown that the use of many drugs is connected to negative health outcomes such as adverse drug reactions, interactions, poor patient adherence and hospitalisations $(10,17,19,26,32,45-49)$. We have previously shown that the number of drugs on admission to hospital is an independent risk factor for the occurrence of drug-related problems, like for example wrong drug choice, non-optimal dosage, adverse drug reactions, drug interactions and non-adherence (50). The number of drug-related problems increased nearly linearly with the number of drugs used (36), a relationship which existed also when the patients used less than five drugs, i.e. polypharmacy according to the traditional definition was not present (Figure 2). This is in line with recent observations of Steinman et al. who in a study among elderly outpatients using five or more drugs, assessed prescribing quality by applying both the Medication Appropriate Index and Beers criteria. They reported that the frequency of inappropriate medication use increased with increasing number of medications (5).

Another negative aspect connected to polypharmacy is costs, both the direct costs for the medications and costs related to evoked negative health outcomes (51). The recognition of these facts has resulted in programmes aiming at better drug therapy along with cost savings. In the US, the introduction of the Medication Therapy Management Program reduced therapy problems in nursing home patients, and in addition, the programme was cost beneficial based solely on drug savings $(38,52)$. However, these results can not, without reservations, be expected to be valid for other countries since the organisation of health care and nursing homes may differ significantly.

\section{UNDERUSE OF MEDICATION}

It is possible that being too occupied with the negative aspects of polypharmacy, and trying to avoid the use of many drugs, may lessen attention to the issue of providing all necessary drugs to an individual patient. This will be the other side of polypharmacy, i.e polypharmacy has two faces - and thus appears as a Janus face. Paying too much focus on keeping a short drug list may influence the search for a patient's complete drug list, for instance by not actively gathering information from all sources that might possess information on drug use. This aspect is particularly important when a patient changes the level of care, for example from nursing home to hospital, because it is known that there are discrepancies between the different sources providing drug overviews for patients $(53,54)$. Furthermore, efforts to maximize the benefit of drugs, for 


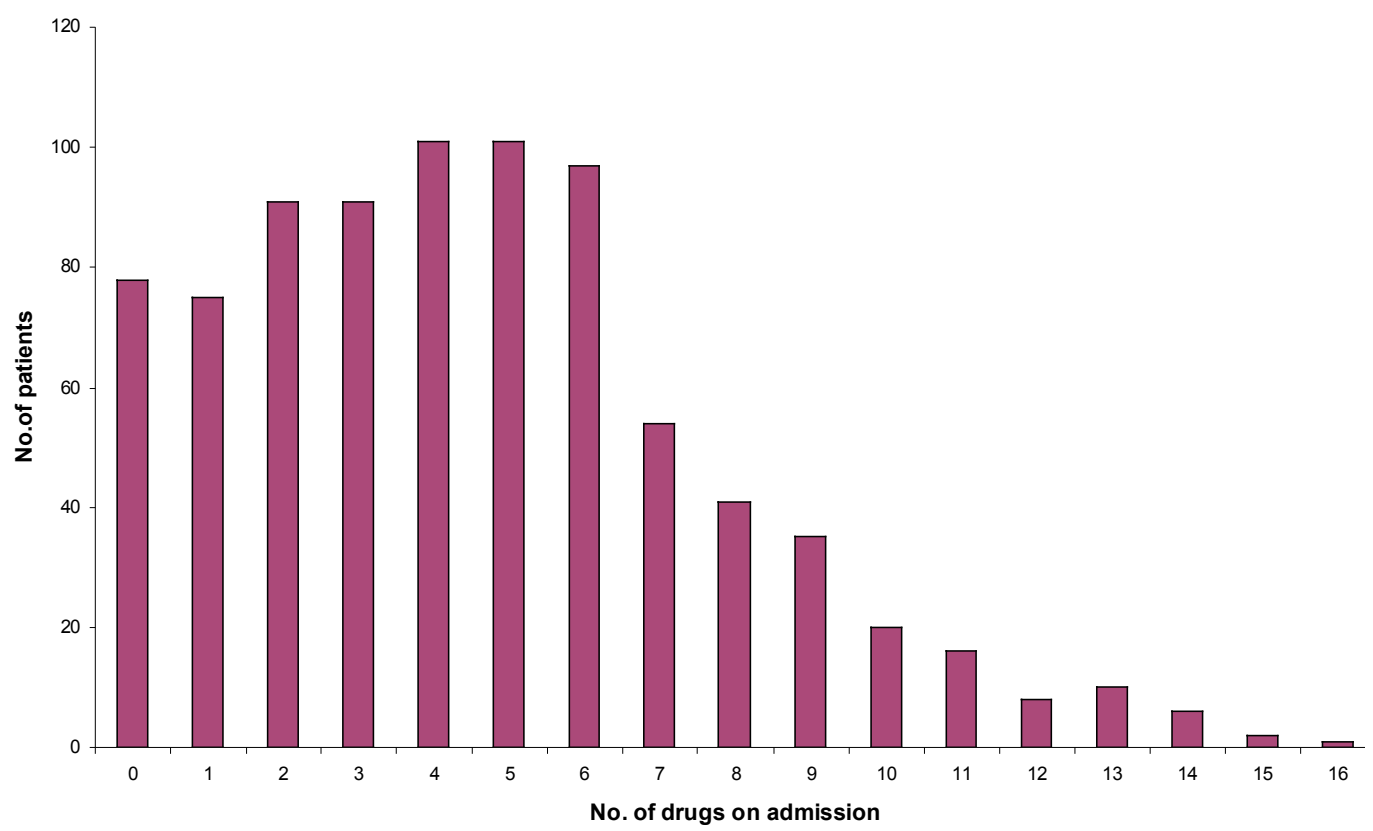

Figure 1. Distribution of drug use on admission among 827 patients hospitalized patients. From: Viktil KK et al. Polypharmacy as commonly defined is an indicator of limited value in the assessment of drug-related problems. Br J Clin Pharmacol 2007; 63: 187-95 (36).

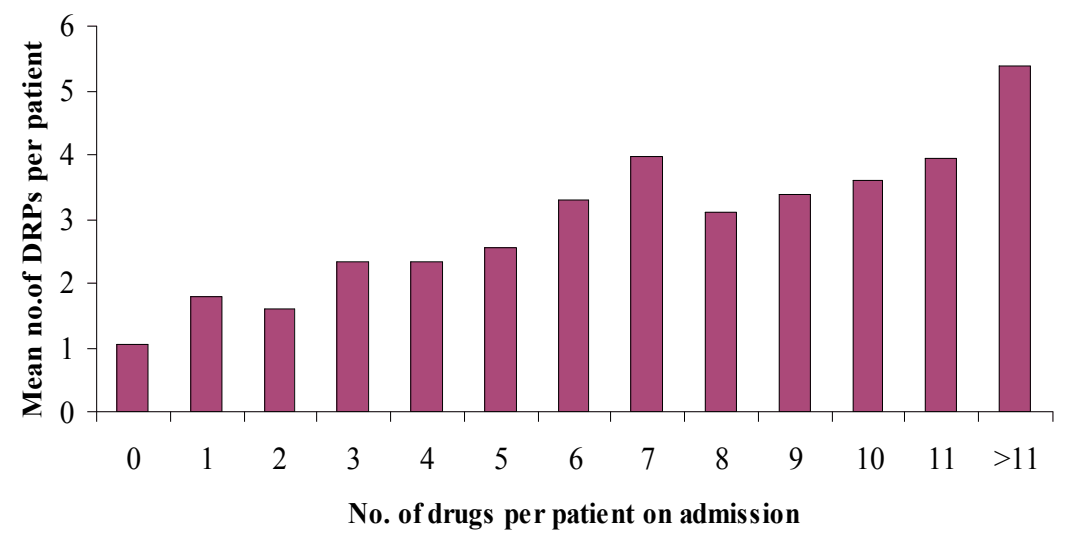

Figure 2. Frequency of drug-related problems (DRPs) per patient in relation to number of drugs used on admission (among 827 patients). DRPs per patient include both DRPs related to drugs on admission and DRPs originating from drugs commenced in hospital.

From: Viktil KK et al. Polypharmacy as commonly defined is an indicator of limited value in the assessment of drug-related problems. Br J Clin Pharmacol 2007; 63: 187-95 (36).

instance by adding drugs to an existing drug regimen for heart failure, may not be whole-heartedly exercised, as this could result in a longer drug list.

Instead of searching for undesirable polypharmacy the focus could be turned around, and a potential for undertreatment, that is prescribing too few drugs, could come to the fore. Studies have investigated undertreatment of various diseases, for instance in heart failure, myocardial infarction and osteoporosis. The findings are that many patients do not receive the medication they need (40,55-59). For example, patients treated for chronic medical diseases are often undertreated when it comes to other unrelated disorders (59). In the study of Steinman et al. referred to above (5) underuse of an average of 1.0 drug per patient was observed among elderly outpatients using five or more drugs. And, notably, this number did not vary with the total number of drugs taken (5). Both inappropriate medication use and underuse were common in older patients and were present simultaneously in more than $40 \%$ of the patients (5). Hence, the awareness of underuse is important regardless of the total number of medications taken.

In a recent study on the relationship between polypharmacy and underprescribing among elderly patients admitted to day-hospital and geriatric wards, underprescribing was observed in $31 \%$ of the patients (24). Further, it was found that patients with polypharmacy, defined as the use of five or more drugs, had a higher frequency of underprescription, $43 \%$, 
than patients using fewer than five drugs, in whom underprescribing was recorded in $13.5 \%$. Interestingly, in this study a clear relationship between the number of drugs used and underuse was observed. The probability of underprescription increased significantly with increase in the number of drugs used.

In conclusion, it is important to recognize underuse, which can be present regardless of the total number of medications taken. Awareness of these relationships and knowledge of the consequences of undertreatment add a new dimension to the approach to polypharmacy - this deals with the Janus face of polypharmacy.

\section{POLYPHARMACY AS INDICATOR}

The presence of polypharmacy is associated with a negative perception of quality. If polypharmacy, using the most common definition, is to be used as a quality indicator in the surveillance of patient populations, more than half of the patients would have been defined as receiving care of poor quality. Furthermore, if when assessing the quality of drug prescribing, a main focus is polypharmacy, one might fail to spot inappropriate drug use in patients using few medications. The following example from clinical practice underlines the point: A 57 years old man using lithium and a sleeping pill - i.e only two drugs - was admitted to hospital with acute painful polyarthritis and diarrhoea. He was given a non-steroidal anti-inflammatory drug (NSAID) to relieve the acute polyarthritis. Since he used few drugs - now three drugs - his drug regimen was not especially paid attention to. However, there is a severe interaction between NSAIDs and lithium, giving rise to a markedly increased blood concentration of lithium and an accompanying risk of renal injury. This illustrates that it is more important to focus on the type of drug and patient specific factors rather than the number of drugs.

The use of a cut-off, for instance five drugs, to define polypharmacy could be questioned more today than some years ago, since many of today's therapeutic guidelines recommend several drugs to achieve most benefit. Recently, we have studied the value of using a definite number of drugs as a cut-off to describe polypharmacy as a risk factor for the occurrence of drug-related problems (36). The approximately linear relationship between number of problems and number of drugs did not show a levelling off of the effect at any specific number of drugs up to eleven drugs.
The relationship between the use of an increasing number of drugs and increased number of drug-related problems, of which underuse is one, was strong. Thus the arbitrariness of using a cut-off of 5 drugs to define polypharmacy was clearly demonstrated.

These findings might also be viewed along with the reports that underprescribing frequently exists together with polypharmacy, and that underprescribing in fact might increase with the use of an increasing number of drugs (24). Thus, the extensive use of polypharmacy as an indicator and also the significance attributed to this factor has not been based on research. Research evidence is lacking. Further, the significance of using many drugs - polypharmacy - as an indicator vis-à-vis application of other indicators (risk factors) such as age, reduced renal function or co-morbidity has not been accurately delineated. This would be an interesting research topic.

\section{CONCLUDING COMMENTS}

From a clinical point of view, our experience is that many patients do not receive all the drugs they should, based on their clinical condition and according to guidelines. Therefore, we felt that the negative connotation associated with the term polypharmacy needed scrutiny. As there is no concise definition of the term, it should be used with caution. More precise terms should be used for describing patients' drug use. For example, appropriateness/inappropriateness and drugrelated problems could be more informative, although they will need particular explanations whenever they are used.

Polypharmacy as a marker for disease burden also needs investigation, and more in-depth understanding of the relationship is needed. More research is required to explore the common perception that use of many drugs contributes significantly to negative health outcomes. Probably, most often it is the disease condition itself that bears the responsibility for poor outcome.

We have not intended to give an overview of all aspects of polypharmacy, but to highlight that polypharmacy has more than one face - it could be looked upon as a Janus face in drug management. There is a fine line between providing an individual patient with appropriate drugs, which might reduce the risk of death or improve quality of life, and the overuse of drugs.

\section{REFERENCES}

1. Hanlon JT, Weinberger M, Samsa GP, Schmader KE, Uttech KM, Lewis IK, et al. A randomized, controlled trial of a clinical pharmacist intervention to improve inappropriate prescribing in elderly outpatients with polypharmacy. Am J Med 1996; 100: 428-37.

2. Denneboom W, Dautzenberg MG, Grol R, De Smet PA. Treatment reviews of older people on polypharmacy in primary care: cluster controlled trial comparing two approaches. Br J Gen Pract 2007; 57: 723-31. 
3. Fillit HM, Futterman R, Orland BI, Chim T, Susnow L, Picariello GP, et al. Polypharmacy management in Medicare managed care: changes in prescribing by primary care physicians resulting from a program promoting medication reviews. Am J Manag Care 1999; 5: 587-94.

4. Finkers F, Maring JG, Boersma F, Taxis K. A study of medication reviews to identify drug-related problems of polypharmacy patients in the Dutch nursing home setting. J Clin Pharm Ther 2007; 32: 469-76.

5. Steinman MA, Landefeld CS, Rosenthal GE, Berthenthal D, Sen S, Kaboli PJ. Polypharmacy and prescribing quality in older people. J Am Geriatr Soc 2006; 54: 1516-23.

6. Steinman MA, Rosenthal GE, Landefeld CS, Bertenthal D, Sen S, Kaboli PJ. Conflicts and concordance between measures of medication prescribing quality. Med Care 2007; 45: 95-9.

7. Bjerrum L, Sogaard J, Hallas J, Kragstrup J. Polypharmacy in general practice: differences between practitioners. Br J Gen Pract 1999; 49: 195-8.

8. Masoudi FA, Krumholz HM. Polypharmacy and comorbidity in heart failure. Br Med J 2003; 327: 513-4.

9. Wawruch M, Zikavska M, Wsolova L, Kuzelova M, Tisonova J, Gajdosik J, et al. Polypharmacy in elderly hospitalised patients in Slovakia. Pharm World Sci 2007; DOI 10.1007/s1 1096-007-9166-3.

10. Frazier SC. Health outcomes and polypharmacy in elderly individuals: an integrated literature review. $J$ Gerontol Nurs 2005; 31: 4-11.

11. Friel JP. Dorland's Illustrated Medical Dictionary, 25th edn. Saunders Company, 1974.

12. Fulton MM, Allen ER. Polypharmacy in the elderly: a literature review. J Am Acad Nurse Pract 2005; 17: 123-32.

13. Bjerrum L, Rosholm JU, Hallas J, Kragstrup J. Methods for estimating the occurrence of polypharmacy by means of a prescription database. Eur J Clin Pharmacol 1997; 53: 7-11.

14. Zarowitz BJ, Stebelsky LA, Muma BK, Romain TM, Peterson EL. Reduction of high-risk polypharmacy drug combinations in patients in a managed care setting. Pharmacotherapy $2005 ; 25: 1636-45$.

15. Brager R, Sloand E. The spectrum of polypharmacy. Nurse Pract 2005; 30: 44-50.

16. Faries D, Ascher-Svanum H, Zhu B, Correll C, Kane J. Antipsychotic monotherapy and polypharmacy in the naturalistic treatment of schizophrenia with atypical antipsychotics. BMC Psychiatry 2005; 5: 26.

17. Fastbom J. Increased consumption of drugs among the elderly results in greater risk of problems. Läkartidningen 2001; 98: 1674-9.

18. Monane M, Monane S, Semla T. Optimal medication use in elders. Key to successful aging. West J Med 1997; 167: 233-7.

19. Lee RD. Polypharmacy: a case report and new protocol for management. J Am Board Fam Pract 1998; 11: $140-4$.

20. Ananth J, Parameswaran S, Gunatilake S. Antipsychotic polypharmacy. Curr Pharm Des 2004; 10: $2231-8$.

21. Preskorn SH, Lacey RL. Polypharmacy: when is it rational? J Psychiatr Pract 2007; 13: 97-105.

22. Jensen GL, Friedmann JM, Coleman CD, Smiciklas-Wright H. Screening for hospitalization and nutritional risks among community-dwelling older persons. Am J Clin Nutr 2001; 74: 201-5.

23. Cross RK, Wilson KT, Binion DG. Polypharmacy and Crohn's disease. Aliment Pharmacol Ther 2005; 21: 1211-6.

24. Kuijpers MA, van Marum RJ, Egberts AC, Jansen PA. Relationship between polypharmacy and underprescribing. Br J Clin Pharmacol 2008; 65: 130-3.

25. Linjakumpu T, Hartikainen S, Klaukka T, Veijola J, Kivela SL, Isoaho R. Use of medications and polypharmacy are increasing among the elderly. J Clin Epidemiol 2002; 55: 809-17.

26. Alarcon T, Barcena A, Gonzalez-Montalvo JI, Penalosa C, Salgado A. Factors predictive of outcome on admission to an acute geriatric ward. Age Ageing 1999; 28: 429-32.

27. Jyrkka J, Vartiainen L, Hartikainen S, Sulkava R, Enlund H. Increasing use of medicines in elderly persons: a five-year follow-up of the Kuopio 75+ Study. Eur J Clin Pharmacol 2006; 62: 151-8.

28. Fincke BG, Snyder K, Cantillon C, Gaehde S, Standring P, Fiore L, et al. Three complementary definitions of polypharmacy: methods, application and comparison of findings in a large prescription database. Pharmacoepidemiol Drug Safety 2005; 14: 121-8.

29. Salazar JA, Poon I, Nair M. Clinical consequences of polypharmacy in elderly: expect the unexpected, think the unthinkable. Expert Opin Drug Saf 2007; 6: 695-704.

30. Williams ME, Pulliam CC, Hunter R, Johnson TM, Owens JE, Kincaid J, et al. The short-term effect of interdisciplinary medication review on function and cost in ambulatory elderly people. J Am Geriatr Soc 2004; 52: 93-8.

31. Jameson JP, VanNoord GR. Pharmacotherapy consultation on polypharmacy patients in ambulatory care. Ann Pharmacother $2001 ; 35$ : 835-40.

32. Flaherty JH, Perry HM, III, Lynchard GS, Morley JE. Polypharmacy and hospitalization among older home care patients. J Gerontol A Biol Sci Med Sci 2000; 55: M554-M559. 
33. Jorgensen T, Johansson S, Kennerfalk A, Wallander MA, Svardsudd K. Prescription drug use, diagnoses, and healthcare utilization among the elderly. Ann Pharmacother 2001; 35: 1004-9.

34. Viktil KK, Enstad M, Kutschera J, Smedstad LM, Schjott J. Polypharmacy among patients admitted to hospital with rheumatic diseases. Pharm World Sci 2001; 23: 153-8.

35. Viola R, Csukonyi K, Doro P, Janka Z, Soos G. Reasons for polypharmacy among psychiatric patients. Pharm World Sci 2004; 26: 143-7.

36. Viktil KK, Blix HS, Moger TA, Reikvam A. Polypharmacy as commonly defined is an indicator of limited value in the assessment of drug-related problems. Br J Clin Pharmacol 2007; 63: 187-95.

37. Perri M, III, Menon AM, Deshpande AD, Shinde SB, Jiang R, Cooper JW, et al. Adverse outcomes associated with inappropriate drug use in nursing homes. Ann Pharmacother 2005; 39: 405-11.

38. Christensen D, Trygstad T, Sullivan R, Garmise J, Wegner SE. A pharmacy management intervention for optimizing drug therapy for nursing home patients. Am J Geriatr Pharmacother 2004; 2: 248-56.

39. Lawlor DA, Patel R, Ebrahim S. Association between falls in elderly women and chronic diseases and drug use: cross sectional study. BMJ 2003; 327: 712-7.

40. Klarin I, Fastbom J, Wimo A. A population-based study of drug use in the very old living in a rural district of Sweden, with focus on cardiovascular drug consumption: comparison with an urban cohort. Pharmacoepidemiol Drug Safety 2003; 12: 669-78.

41. Kennerfalk A, Ruigomez A, Wallander MA, Wilhelmsen L, Johansson S. Geriatric drug therapy and healthcare utilization in the United Kingdom. Ann Pharmacother 2002; 36: 797-803.

42. Ikaheimo P, Hartikainen S, Tuuponen T, Kiuttu J, Klaukka T. Comorbidity and medication load in adult asthmatics. Scand J Prim Health Care 2005; 23: 88-94.

43. Geest SD, Steeman E, Leventhal ME, Mahrer-Imhof R, Hengartner-Kopp B, Conca A, et al. Complexity in caring for an ageing heart failure population: concomitant chronic conditions and age related impairments. Eur J Cardiovasc Nurs 2004; 3: 263-70.

44. Jorgensen T, Johansson S, Kennerfalk A, Wallander MA, Svardsudd K. Prescription drug use, diagnoses, and healthcare utilization among the elderly. Ann Pharmacother 2001; 35: 1004-9.

45. Hayes BD, Klein-Schwartz W, Barrueto F, Jr. Polypharmacy and the geriatric patient. Clin Geriatr Med 2007; 23: 371-90.

46. Hanlon JT, Schmader KE, Koronkowski MJ, Weinberger M, Landsman PB, Samsa GP, et al. Adverse drug events in high risk older outpatients. J Am Geriatr Soc 1997; 45: 945-8.

47. van den Bemt PM, Egberts AC, Lenderink AW, Verzijl JM, Simons KA, van der Pol WS, et al. Risk factors for the development of adverse drug events in hospitalized patients. Pharm World Sci 2000; 22: 62-6.

48. Stewart RB, Cooper JW. Polypharmacy in the aged. Practical solutions. Drugs Aging 1994; 4: 449-61.

49. Veehof LJG, Meyboom-de JB, Haaijer-Ruskamp FM. Polypharmacy in the elderly - A literature review. Eur J General Pract 2000; 6: 98-106.

50. Blix HS, Viktil KK, Reikvam A, Moger TA, Hjemaas BJ, Pretsch P, et al. The majority of hospitalised patients have drug-related problems: results from a prospective study in general hospitals. Eur J Clin Pharmacol 2004; 60: 651-8.

51. Rollason V, Vogt N. Reduction of polypharmacy in the elderly: a systematic review of the role of the pharmacist. Drugs Aging 2003; 20: 817-32.

52. Trygstad TK, Christensen D, Garmise J, Sullivan R, Wegner S. Pharmacist response to alerts generated from Medicaid pharmacy claims in a long-term care setting: results from the North Carolina polypharmacy initiative. J Manag Care Pharm 2005; 11: 575-83.

53. Myhr R, Kimsas A. [Medication errors when transferring within health care services]. Tidsskr Nor Laegeforen 1999; 119: 1087-91.

54. Due Larsen M, Nielsen LP, Jeffery L, Staehr ME. Medicineringsfejl ved indleggelse på danske sygehus. Ugeskr Lager 2006; 168: 2887-90.

55. Gurwitz JH. Polypharmacy: a new paradigm for quality drug therapy in the elderly? Arch Intern Med 2004; 164: 1957-9.

56. Jackson HD, Mangoni AA, Batty GM. Optimization of drug prescribing. Br J Clin Pharmacol 2004; 57: 231-6.

57. Skrepnek GH, Abarca J, Malone DC, Armstrong EP, Shirazi FM, Woosley RL. Incremental effects of concurrent pharmacotherapeutic regimens for heart failure on hospitalizations and costs. Ann Pharmacother 2005; 39: 1785-91.

58. Sloane PD, Gruber-Baldini AL, Zimmerman S, Roth M, Watson L, Boustani M, et al. Medication undertreatment in assisted living settings. Arch Intern Med 2004; 164: 2031-7.

59. Redelmeier DA, Tan SH, Booth GL. The treatment of unrelated disorders in patients with chronic medical diseases. N Engl J Med 1998; 338: 1516-20. 